\title{
Treating Chronic Pain with Mesenchymal Stem Cells: A Therapeutic Approach Worthy of Continued Investigation
}

\section{Ruth S Waterman ${ }^{1 *}$ and Aline M Betancourt ${ }^{2}$}

${ }^{1}$ Ochsner Clinic Foundation, New Orleans, LA UNITED STATES

${ }^{2}$ Tulane University School of Medicine, USA

\begin{abstract}
Though there are various etiologies to chronic pain, one common feature is that painful states are associated with increased inflammation. This is verified by studies in both animal models and humans that have found increased expression of inflammatory proteins in muscle tissue, and increased inflammatory cytokines in cerebral spinal fluid, synovial fluid, and serum. Over the last decade we have become aware of the anti-inflammatory effects that multipotent mesenchymal stromal cells frequently referred to as mesenchymal stem cells [MSC], elicit. This ability of MSC to affect the inflammatory milieu has led researchers to consider MSC as a treatment for various painful states such as degenerative disc disease and osteoarthritis. In this article we present relevant animal and human studies, which indicate that MSC are worthy of further study as a valuable therapy in the treatment of chronic pain.
\end{abstract}

\section{Introduction}

Pain is widespread in the United States and it has an enormous impact on society. Although the number of people suffering with pain is difficult to precisely identify, it is estimated that over 115 million people suffer from chronic pain [1]. This represents a patient population larger than the combined numbers for those suffering with diabetes, stroke, cancer, and coronary heart disease. Individuals with pain also affect the nation's productivity. The annual value of lost productivity is gauged to be between $\$ 297$ and $\$ 333$ billion. Back pain alone is estimated to cost employers over $\$ 7$ billion per year [2]. Additionally, the pain from arthritis flare-ups is calculated to cost $\$ 7.11$ billion annually in lost productive time [3]. The burden of pain to patients and society has become so extreme that the National Institute of Medicine has recommended that alleviation of pain become a national priority [1].

\section{Pain and inflammation}

It is well recognized that inflammation plays a role in a variety of pain states at both the peripheral and central levels, and the idea that chronic pain is associated with aberrant inflammation is quickly gaining more acceptance. Numerous sources have verified an increase in pro-inflammatory cytokines such as interleukin [IL]-1, IL-2, IL-6, IL-17, and tumor necrosis factor [TNF]- $\alpha$ in various pain states [4-6]. The pro-inflammatory cytokine IL- 6 has been detected in synovial fluid of patients with osteoarthritis [6], while TNF- $\alpha$ has been implicated in modifying pain perception [7]. In the synovial fluid of rheumatoid arthritis patients, IL-17 has been found to be elevated [8,9]. In contrast, IL-17 knockout mice failed to develop arthritis [10]. An additional study showed that IL-17 deficient mice had decreased neuropathic pain after peripheral nerve injury compared to those mice capable of expressing IL-17 [11]. In the central nervous system, microglias have been implicated in releasing pro-inflammatory cytokines such as IL-6, TNF- $\alpha$, and IL-1 $\beta$, which contribute to neuropathic pain [12]. Additionally, it has been shown that microglia play a role in chronic pain by activating astrocytes that sustain inflammation [13]. Because of the association between chronic neuropathic pain and immune responses, it has been suggested that neuropathic pain be referred to as neuro-immune pain [14].

\section{Current therapies for chronic pain}

Many therapies have been directed towards decreasing the inflammatory state or blocking the pain pathway with only minimal improvements in pain. Subsequently, patients are often left with few options that include chronic medication usage or invasive procedures that yield minimal results. Based on studies, lumbar decompression surgery has a suggested failure rate of approximately 35\%. Despite advances in surgical techniques, the rate of failed back surgery syndrome has not decreased in the last decades [15]. An extensive 2011 review found that the use of opioids for the treatment of chronic non-cancer pain resulted in only a minor improvement in pain and function when compared to taking a placebo [16]. Moreover, opioids have unpleasant side effects that include drowsiness, dependence, constipation, nausea, and pruritus [17]. If used chronically, opioids can even lead to endocrine dysfunction [18]. Additionally, the chronic use of opioids can lead to hyperalgesia. This has been linked to $m u$ opioid receptors' release of pro-inflammatory mediators, which increase the levels of IL-1 $\beta$, IL- 6 , and TNF- $\alpha[19,20]$. The use of non-steroidal anti-inflammatory drugs [NSAIDs] in patients with either symptomatic acute or chronic low back pain and no sciatica has shown to be more effective in providing short-term pain relief than narcotics, muscle relaxants, or acetaminophen. No particular NSAID appears to provide better relief than another, and the use of this class of drugs also has the risk of gastrointestinal side effects and, in specific NSAIDs, cardiovascular complications [21]. Glucocorticoids are often used in injectable form to alleviate pain at joints. These drugs inhibit a wide range of cytokines and chemokines [22]. However, their duration of action is unpredictable with a literature review revealing that there is moderate evidence for caudal epidural steroid injections providing pain relief lasting longer than 6 weeks [23]. In addition, there is the potential for adverse reactions: hyperglycemia, blood pressure

${ }^{*}$ Corresponding author: Ruth S Waterman, Ochsner Clinic Foundation, New Orleans, LA UNITED STATES, E-mail: Ibdrsw@gmail.com

Received September 15, 2011; Accepted October 19, 2011; Published October 21, 2011

Citation: Waterman RS, Betancourt AM (2011) Treating Chronic Pain with Mesenchymal Stem Cells: A Therapeutic Approach Worthy of Continued Investigation. J Stem Cell Res Ther S2:001. doi:10.4172/2157-7633.S2-001

Copyright: (c) 2011 Waterman RS, et al. This is an open-access article distributed under the terms of the Creative Commons Attribution License, which permits unrestricted use, distribution, and reproduction in any medium, provided the original author and source are credited. 
fluctuations, Cushing's syndrome, bone demineralization, and steroid induced psychosis [24-26]. For patients enduring chronic pain from rheumatoid arthritis, disease-modifying antirheumatic drugs [DMARDs] are often prescribed. While these target inflammation, they also have systemic effects that include gastrointestinal disturbances, liver and kidney toxicity, increased risk of infection, and pancytopenia [27]. Painful diabetic peripheral neuropathy is a common complication of diabetes mellitus. Recent guidelines by the American Academy of Neurology for the treatment of painful diabetic peripheral neuropathy place only pregabalin in the level A recommendation tier [28]. This anti-epileptic medication binds to voltage gated calcium channels and attenuates the influx of calcium in neurons. The resultant effect is a decrease in the release of norepinephrine, substance $P$, and glutamate [29]. Substance P is known to augment the production of IL-1 $\beta$, IL6 , and TNF- $\alpha$, all pro-inflammatory cytokines [30]. Therefore, it is plausible that the inflammatory modifying effects of pregabalin contribute to the improvement seen in those patients receiving this medication for painful diabetic peripheral neuropathy. Side effects of pregabalin include somnolence, sedation, visual disturbances, and dry mouth [31].

\section{Mesenchymal stem cells and inflammation}

Mesenchymal stem cells [MSC] is the conventional term used to describe the collection of poorly defined multipotent mesenchymal stromal cells [32], and as such, this misnomer will be used in this paper. In a recent article, Singer and Caplan presented a review on MSCs that outlined their effects on the immune system. Specifically, that MSCs have anti-inflammatory effects, that they inhibit dendritic cell [DC] maturation and $\mathrm{B}$ and $\mathrm{T}$ cell proliferation and differentiation, that they attenuate natural killer [NK] cell killing, and that they also support suppressive T regulatory cells [Tregs]. MSCs also decrease the amount of IL-10 and TNF- $\alpha$ secreted by DC cells, and increase the amount of the anti-inflammatory IL- 4 produced by T cells [33]. MSC-based therapies have had some success in clinical trials of diseases ranging widely from graft-versus-host to joint and cartilage disorders [32,34]. MSCs are capable of attenuating the inflammatory milieu; however, the exact mechanism by which this takes place is yet to be precisely defined. Growing evidence suggests that they naturally home to sites of injury, but do not engraft in the injured tissue [32-36]. Additionally, MSC-based therapies are attractive new treatment candidates because they do not express immune co-stimulatory molecules that can elicit host rejection or immunity [32-36]. This should decrease the incidence of graft rejection even in xenotransplantation, and allow for the use of both self [autologous] or non-self [allogeneic] MSC in future therapeutics $[32,34]$. The above characteristics make MSC attractive as a treatment for chronic pain.

\section{Animal studies linking pain and inflammation}

Various studies in animal models have linked increased proinflammatory cytokines to painful states (Table 1). Kato and colleagues investigated the effects of etanercept, a TNF antagonist, on neuropathic pain in rats. They found that in injured neurons, etanercept was able to reach the endoneurium; however, it did not do so in uninjured neurons. After local injection of entanercept into rats with sciatic nerve crush injury, behavioral assays showed improvement of pain [37]. Another study in rats revealed that in animals with injured L5 nerve roots TNF- $\alpha$ was increased [38]. Three reports in separate animal models from 2007 associated increased levels of pro-inflammatory cytokines with the development of osteoarthritis [OA] [39-41] Maccoux and colleagues found that in the synovial fluid of dogs with OA, levels of IL-1 $\beta$, IL-6, and IL-10 were increased [39]. The synovial fluid from the joints of horses that had OA was assayed and found to have elevated levels of IL-6 [40]. In guinea pig models of OA, Huebner and peers found that the levels of IL- 6 were higher in the serum of animals with disease [41]. IL-17 is a pro-inflammatory cytokine believed to have a role in the development of inflammatory states. In studies using mice models deficient in IL-17, there was the failure of IL-17 knockout mice to develop arthritis in one of the studies; while in the other, the lack if IL-17 resulted in decreased neuropathic pain $[10,11]$. A recent mouse study examined spinal astrocyte activation in diabetic neuropathic pain. It concluded that the activation of the astrocytes resulted in increased IL-1 $\beta$ and was likely a contributor to the increased pain transmission found in neuropathic pain [42]. IL21 , a cytokine with pro-inflammatory properties has recently been implicated in rheumatoid arthritis. When researchers attempted to induce inflammatory arthritis in a mouse model deficient for IL-21, they were unsuccessful [43].

\section{Human studies linking pain and inflammation}

Many human studies of diseases that cause pain have shown an increase in specific inflammatory markers (Table 2). Orita and colleagues evaluated the knee synovial fluid in 47 patients with OA. They found elevated IL- 6 and TNF- $\alpha$ in knee joints of OA patients [44]. In 2011, Levinger et al. reported that greater levels of IL-6 protein and increased expression of TNF- $\alpha$ and IL- $1 \beta$ were present in the vastus lateralis muscle of patients with osteoarthritis when compared to control patients [45]. Kim and colleagues evaluated cartilage from patients with $\mathrm{OA}$ and compared it to normal donors. They found that in samples from both groups TNF- $\alpha$ and IL- $1 \beta$ disrupted mitochondrial function and led to the death of cartilage cells; however, the mitochondria from the OA group were more readily damaged by the pro-inflammatory cytokines than were the samples from normal

\begin{tabular}{|l|l|c|l|l|}
\hline \multicolumn{1}{|c|}{ Year } & \multicolumn{1}{|c|}{ Authors } & Animal Model & \multicolumn{1}{c|}{ Disease } & \multicolumn{1}{c|}{ Inflammatory Findings } \\
\hline 2003 & Nakae, et al. & Mouse & Arthritis & IL-17 deficient mice did not develop arthritis \\
\hline 2007 & Maccoux, et al. & Dog & Osteoarthritis & Increased IL-1 $\beta$, IL-6, IL-10 in synovial fluid \\
\hline 2007 & Ley, et al. & Horse & Osteoarthritis & Increased IL-6 in synovial fluid \\
\hline 2007 & Huebner, et al. & Guinea Pig & Osteoarthritis & Increased IL-6 in serum \\
\hline 2009 & Kato, et al. & Rat & Neuropathic Pain & Decreased TNF- $\alpha$ expression correlated with less pain \\
\hline 2009 & Sekiguchi, et al. & Rat & Neuropathic Pain & Increased TNF- $\alpha$ in L5 nerve root injury \\
\hline 2011 & Liao, et al. & Mouse & Neuropathic Pain & Increased IL-1 $\beta$ expression in spinal cord \\
\hline 2011 & Kim, et al. & Mouse & Neuropathic Pain & Lack of IL-17 resulted in decreased pain \\
\hline 2011 & Yuan, et al. & Mouse & Arthritis & IL-21 deficient mice did not develop arthritis \\
\hline
\end{tabular}




\begin{tabular}{|c|l|l|l|l|}
\hline Year & \multicolumn{1}{|c|}{ Authors } & \multicolumn{1}{|c|}{ Disease } & \multicolumn{1}{|c|}{ Inflammatory Findings } \\
\hline 2005 & Alexander et al. & Complex Regional Pain Syndromes & Cerebral Spinal Fluid & Increased IL-6 and IL-1 $\beta$ \\
\hline 2007 & Uceyler, et al. & Complex Regional Pain Syndromes & Serum & Increased IL-2 and TNF- $\alpha$. Decreased anti-inflammatory IL-4 and IL-10 \\
\hline 2009 & Doupis, et al. & Painful Diabetic Peripheral Neuropathy & Serum & $\begin{array}{l}\text { Higher levels of TNF- } \alpha \text { in painful versus painless diabetic peripheral } \\
\text { neuropathy }\end{array}$ \\
\hline 2009 & Lee, et al. & Degenerative Disc Disease & Intervertebral Disc & Higher levels of TNF- $\alpha$ and IL-8 \\
\hline 2010 & Kraychete, et al. & Herniated Disc & Serum & Greater levels of IL-6 and TNF- $\alpha$ \\
\hline 2010 & Cuellar, et al. & Degenerative Disc Disease & Disc Fluid & Increased IFN-gamma \\
\hline 2010 & Kim, et al. & Osteoarthritis & Cartilage & $\begin{array}{l}\text { TNF- } \alpha \text { and IL-1 } 1 \beta \text { caused more damage to mitochondria of OA tissue } \\
\text { than normal tissue }\end{array}$ \\
\hline 2011 & Levinger, et al. & Osteoarthritis & Muscle & Higher levels of IL-6, IL-1 $\beta$, and TNF- $\alpha$ \\
\hline 2011 & Purwata, et al. & Painful Diabetic Peripheral Neuropathy & Serum & Higher levels of TNF- $\alpha$ \\
\hline 2011 & Orita, et al. & Osteoarthritis & Synovial Fluid & Higher levels of IL-6 and TNF- $\alpha$ \\
\hline
\end{tabular}

IL=interleukin, TNF=tumor necrosis factor

Table 2: Human Studies and Inflammation.

\begin{tabular}{|c|l|l|c|l|l|}
\hline Year & \multicolumn{1}{|c|}{ Authors } & \multicolumn{1}{|c|}{ Disease } & Model & \multicolumn{1}{|c|}{ Therapy } & Findings \\
\hline 2008 & Alfaqeh, et al. & Osteoarthritis & Sheep & Autologous MSC injection & Articular cartilage regeneration \\
\hline 2008 & Shibata, et al. & Diabetic Polyneuropathy & Rat & Autologous MSC injection & $\begin{array}{l}\text { Improved hypoalgesia, sural nerve blood flow, and nerve conduction } \\
\text { velocity }\end{array}$ \\
\hline 2008 & Centeno, et al. & Osteoarthritis & Human & Autologous MSC injection & Regeneration of meniscus cartilage \\
\hline 2010 & Yoshikawa, et al. & Degenerative Disc Disease & Human & Autologous MSC injection & Disc regeneration and decrease in back and leg pain \\
\hline 2011 & Orozco, et al. & Degenerative Disc Disease & Human & Autologous MSC injection & Decrease in pain and disability \\
\hline 2011 & Guo, et al. & Chronic Pain & Rat & Autologous MSC injection & Reversed mechanical hypersensitivity \\
\hline 2011 & $\begin{array}{l}\text { Waterman and } \\
\text { Betancourt }\end{array}$ & $\begin{array}{l}\text { Painful Diabetic Peripheral } \\
\text { Neuropathy }\end{array}$ & Mouse & Human MSC2 injection & $\begin{array}{l}\text { Decreased serum inflammatory cytokines, improved heat } \\
\text { hyperalgesia and mechanical allodynia }\end{array}$ \\
\hline
\end{tabular}

MSC=multipotent mesenchymal stromal cells frequently referred to as mesenchymal stem cells, MSC2=anti-inflammatory mesenchymal stem cells

Table 3: studies of painful conditions and msc therapy.

patients [46]. A comparison study between patients with degenerative disc disease and those with a herniated nucleus pulposus evaluated disc specimens for cytokines. The patients with degenerative disc disease had greater levels of TNF- $\alpha$ and IL- 8 than those patients that only had herniation. The authors posit that this increased cytokine expression could be a contributing factor for the greater pain that is experienced with degenerated discs than with herniation [47]. In a Phase 1 study of patients with symptomatic lumbar degenerative disc disease, the pro-inflammatory marker IFN-gamma was found to be elevated when disc lavage fluid was analyzed. An elevation of IFN-gamma was not found in the lavage fluid of asymptomatic controls [48]. In 23 patients with herniated lumbar intervertebral discs, levels of IL- 6 and TNF- $a$ were elevated when compared to 10 healthy patients [49]. There are also studies that implicate inflammation in painful diabetic peripheral neuropathy. It has been shown that patients with painful versus painless diabetic peripheral neuropathy have higher levels of TNF- $\alpha$ in their serum than those who do not suffer with the painful form of the disease [50,51]. Complex Regional Pain Syndromes [CRPS] result in severe and persistent pain and have been associated with cytokine expression that differs from those without the syndrome. In the cerebrospinal fluid of patients with CRPS, levels of IL- 6 and IL- $1 \beta$ were higher than those of the controls [52]. In a study that evaluated blood from patients with CRPS, the cytokine protein and mRNA levels were higher for IL-2 and TNF- $\alpha$, while the anti-inflammatory cytokines IL- 4 and IL-10 were reduced [53].

\section{Use of stem cells in conditions of chronic pain}

Investigators have recognized the potential for MSC to be utilized in the treatment of painful diseases (Table 3). In a pilot study, 10 patients with degenerative disc disease and low back pain received autologous MSC. The patients' pain and disability decreased to an extent comparable to those who had received spinal fusion or total disc replacement. In addition, MSC therapy offered the advantages of being less invasive and preserving the biomechanics of the lumbar region [54]. In Japan, the autologous injection of MSC into degenerated intervertebral discs yielded disc regeneration and alleviation of back and leg pain [55]. Alfeqeh and peers surgically induced osteoarthritis in a sheep model and then injected autologous MSC into the arthritic knee joints. After six weeks, they found evidence of articular cartilage regeneration in their osteoarthritis model [56]. In 2008, Centeno and colleagues reported their novel findings that the reimplantation of autologous MSC into the knee joint of a patient with OA yielded regeneration of meniscus cartilage [57]. Subsequently, Centeno's group published on the safety of using MSC as a treatment for OA. They performed follow-up MRIs in 227 patients at various time points from 3 months to 2 years status post re-implantation with the MSCs. The MRIs did not reveal any tumor formations at the re-implantation sites [58]. MSC were evaluated as a therapy for persistent pain in a rat model. The tendons of the masseter muscles were ligated to create orofacial mechanical hypersensitivity. MSC were infused through the tail veins at 3 days, 2 months, and 4 months after tendon ligation. The infusions reversed the mechanical hypersensitivity after each injection point [59]. Shibata and peers injected MSC into rats that had streptozotocin-induced diabetes. Post injection of MSC, hypoalgesia, decreased sural nerve blood flow, and nerve conduction velocity, were all improved [60]. Our research has shown that the use of the newly described human anti-inflammatory MSC [MSC2] [61] in a streptozotocin-induced diabetic mouse model improves the behavioral assays of the mice and decreases the pro-inflammatory cytokines IL- $1 \beta$, IL-2, IL-6, IL-17, and TNF- $\alpha$ to a greater degree than untreated MSC [62]. These findings are in agreement with the notion that MSC do not express immune co-stimulatory molecules that elicit immunity or graft rejection even in xenotransplantation [32-36]. 
Citation: Waterman RS, Betancourt AM (2011) Treating Chronic Pain with Mesenchymal Stem Cells: A Therapeutic Approach Worthy of Continued Investigation. J Stem Cell Res Ther S2:001. doi:10.4172/2157-7633.S2-001

\section{Summary}

Pain control is an unmet medical need not only in the United States, but also in the world. The current therapies commonly used are not able to provide all patients with adequate pain control [63]. Research over the last decade has shown both in animal and human models that inflammation and painful states are intertwined. Many of the medications prescribed to patients for pain relief have some antiinflammatory mechanisms; however, such medications often have untoward side effects or are incapable of dampening the immune system at a point where optimal anti-inflammatory effects can be elicited. Mesenchymal stem cells may provide an alternative to current therapies for pain. Their anti-inflammatory effects have been demonstrated in painful diseases ranging from degenerative disc disease to painful diabetic peripheral neuropathy. They also have the following advantages: they have not been associated with adverse events, they target the inflammation at the site of damage, they encourage growth of healthy tissue, they can be administered from either autologous or allogeneic sources, and they are showing positive effects in both neuropathic and musculoskeletal pain. The precise mechanism by which MSC decrease inflammation has yet to be completely outlined, and their long-term effects must be studied. However, because MSC have shown the potential to alleviate pain in various disease processes further investigation into their therapeutic ability is warranted.

\section{References}

1. Institute of Medicine of the National Academies Report (2011) Relieving Pain in America: A Blueprint for Transforming Prevention, Care, Education, and Research, The National Academies Press, Washington DC

2. Ricci J, Stewart W, Chee E, Leotta C, Foley K, et al. (2006) Back pain exacerbations and lost productive time costs in United States workers. Spine 31: $3052-3060$

3. Ricci J, Stewart W, Chee E, Leotta C, Foley K, et al. (2005) Pain exacerbation as a major source of lost productive time in US workers with arthritis. Arthritis Rheum 53: 673-681.

4. de Oliveira C, Sakata R, Issy A, Gerola L, Salomão R (2011) Cytokines and pain. Rev Bras Anestesiol 61: 255-259, 260-265, 137-142.

5. Andrade P, Visser-Vandewalle V, Hoffmann C, Steinbusch H, Daemen M, et al. (2011) Role of TNF- $\alpha$ during central sensitization in preclinical studies. Neurol Sci 32: 757-771.

6. Doss F, Menard J, Hauschild M, Kreutzer HJ, Mittlmeier T, et al. (2007) Elevated IL-6 levels in the synovial fluid of osteoarthritis patients stem from plasma cells. Scand J Rheumatol 36: 136-139.

7. Inoue K, Tsuda M (2009) Microglia and neuropathic pain. Glia 57: 1469-1479.

8. Chabaud M, Durand JM, Buchs N, Fossiez F, Page G, et al. (1999) Human interleukin-17: a $\mathrm{T}$ cell-derived proinflammatory cytokine produced by the rheumatoid synovium. Arthritis Rheum 42: 963-970.

9. Kotake S, Udagawa N, Takahashi N, Matsuzaki K, Itoh K, et al. (1999) IL-17 in synovial fluids from patients with rheumatoid arthritis is a potent stimulator of osteoclasto-genesis. J Clin Invest 103: 1345-1352.

10. Nakae S, Nambu A, Sudo K, Iwakura Y (2003) Suppression of immune induction of collagen-induced arthritis in IL-17-deficient mice. J Immunol 171: 6173-6177.

11. Kim C, Moalem-Taylor G (2011) Interleukin-17 contributes to neuroinflammation and neuropathic pain following peripheral nerve injury in mice. J Pain 12: 370383.

12. Inoue K (2006) The function of microglia through purinergic receptors: neuropathic pain and cytokine release. Pharmacol Ther 109: 210-226.

13. Vallejo R, Tilley D, Vogel L, Benyamin R (2010) The role of glia and the immune system in the development and maintenance of neuropathic pain. Pain Pract 10: $167-184$
14. Austin P, Moalem-Taylor G (2010) The neuro-immune balance in neuropathic pain: involvement of inflammatory immune cells, immune-like glial cells and cytokines. J Neuroimmunol 229: 26-50.

15. Chan C, Peng P (2011) Failed back surgery syndrome. Pain Med 12: 577-606.

16. Turk D, Wilson H, Cahana A (2011) Treatment of chronic non-cancer pain Lancet 377: 2226-2235.

17. Anastassopoulos K, Chow W, Ackerman S, Tapia C, Benson C, et al. (2011) Oxycodone-related side effects: impact on degree of bother, adherence, pain relief, satisfaction, and quality of life. J Opioid Manag 7: 203-215.

18. Katz N, Mazer NA (2009) The impact of opioids on the endocrine system. Clin J Pain 25: 170-175.

19. DeLeo J, Tanga F, Tawfik V (2004) Neuroimmune activation and neuroinflammation in chronic pain and opioid tolerance/hyperalgesia Neuroscientist 10: 40-52

20. Mika J (2008) Modulation of microglia can attenuate neuropathic pain symptoms and enhance morphine effectiveness. Pharmacol Rep 60: 297-307.

21. Roelofs P, Deyo R, Koes B, Scholten R, van Tulder M (2008) Non-steroida anti-inflammatory drugs for low back pain. Cochrane Database Syst Rev 1 CD000396.

22. Zen M, Canova M, Campana C, Bettio S, Nalotto L, et al. (2011) The kaleidoscope of glucorticoid effects on immune system. Autoimmun Rev 10 305-310.

23. Abdi S, Datta S, Trescot A, Schultz D, Adlaka R, et al (2007) Epidural steroids in the management of chronic spinal pain: a systematic review. Pain Physician 10: $185-212$.

24. Product Information: Decadron $®$ phosphate injection, dexamethasone sodium phosphate [1996] Merck \& Co., Inc., West Point, PA, October.

25. Product Information: Kenalog®-40 injection, triamcinolone acetonide [2001] Bristol-Myers Squibb Co., Princeton, NJ, revised April.

26. Benyamin R, Vallejo R, Kramer J, Rafeyan R (2008) Corticosteroid induced psychosis in the pain management setting. Pain Physician 11: 917-920.

27. Majithia V, Geraci S (2007) Rheumatoid arthritis: diagnosis and management. Am J Med 20: 936-939.

28. Bril V, England J, Franklin GM, Backonja M, Cohen J, et al. (2011) Evidencebased guideline: Treatment of painful diabetic neuropathy: report of the American Academy of Neurology, the American Association of Neuromuscular and Electrodiagnostic Medicine, and the American Academy of Physical Medicine and Rehabilitation. Neurology 76: 1758-1765.

29. Kumar N, Laferriere A, Yu J, Leavitt A, Coderre T (2010) Evidence that pregabalin reduces neuropathic pain by inhibiting the spinal release of glutamate. J Neurochem 113: 552-561.

30. Sahbaie P, Shi X, Guo T, Qiao Y, Yeomans D, et al. (2009) Role of substance $P$ signaling in enhanced nociceptive sensitization and local cytokine production after incision. Pain 145: 341-349.

31. Engelman E, Cateloy $F$ (2011) Efficacy and safety of perioperative pregabalin for post-operative pain: a meta-analysis of randomized-controlled trials. Acta Anaesthesiol Scand Jun [Epub ahead of print]

32. Tolar J, Le Blanc K, Keating A, Blazar B (2010) Concise review: hitting the right spot with mesenchymal stromal cells. Stem Cells 28: 1446-1455.

33. Singer N, Caplan A (2011) Mesenchymal stem cells: mechanisms of inflammation. Annu Rev Pathol 6: 457-478

34. Salem H, Thiemermann C (2010) Mesenchymal stromal cells: current understanding and clinical status. Stem Cells 28: 585-596.

35. Bunnell B, Betancourt A, Sullivan D (2010) New concepts on the immune modulation mediated by mesenchymal stem cells. Stem Cell Res Ther 1: 34

36. Prockop, D (2009) Repair of tissues by adult stem/progenitor cells [MSCs] controversies, myths, and changing paradigms. Mol Ther 17: 939-946.

37. Kato K, Kikuchi S, Shubayev V, Myers R (2009) Distribution and tumor necrosis factor-alpha isoform binding specificity of locally administered etanercept into injured and uninjured rat sciatic nerve. Neuroscience 160: 492-500. 
Citation: Waterman RS, Betancourt AM (2011) Treating Chronic Pain with Mesenchymal Stem Cells: A Therapeutic Approach Worthy of Continued Investigation. J Stem Cell Res Ther S2:001. doi:10.4172/2157-7633.S2-001

38. Sekiguchi M, Sekiguchi Y, Konno S, Kobayashi H, Homma Y, et al. (2009) Com-parison of neuropathic pain and neuronal apoptosis following nerve root or spinal nerve compression. Eur Spine J 18: 1978-1985.

39. Maccoux L, Salway F, Day P, Clements D (2007) Expression profiling of select cytokines in canine osteoarthritis tissues. Vet Immunol Immunopathol 118: 59 67.

40. Ley C, Ekman S, Elme'n A, Nilsson G, Eloranta M (2007) Interleukin-6 and tumour necrosis factor in synovial fluid from horses with carpal joint pathology. J Vet Med A Physiol Pathol Clin Med 54: 346-351.

41. Huebner J, Selfer D, Kraus V (2007) A longitudinal analysis of serum cytokines in the Hartley guinea pig model of osteoarthritis. Osteoarthritis Cartilage 15: 354-356

42. Liao Y, Zhang G, Jia D, Wang P, Qian N, et al. (2011) Spinal astrocytic activation contributes to mechanical allodynia in a mouse model of type 2 diabetes. Brain Res 1368: 324-335.

43. Yuan F, Hu W, Lu W, Li X, Li J, et al. (2011) Targeting interleukin-21 in rheumatoid arthritis. Mol Biol Rep 38: 1717-1721

44. Orita S, Koshi T, Mitsuka T, Miyagi M, Inoue G, et al. (2011) Associations between proinflammatory cytokines in the synovial fluid and radiographic grading and pain-related scores in 47 consecutive patients with osteoarthritis of the knee. BMC Musculoskelet Disord 12: 144.

45. Levinger I, Levinger P, Trenerry M, Feller J, Bartlett J, et al. (2011) Increased inflammatory cytokine expression in the vastus lateralis of patients with knee osteoarthritis. Arthritis Rheum 63: 1343-1348.

46. Kim J, Xu M, Xo R, Mates A, Wilson G, et al (2010) Mitochondrial DNA damage is involved in apoptosis caused by pro-inflammatory cytokines in human OA chondrocytes. Osteoarthritis Cartilage 18: 424-432.

47. Lee S, Moon C, Sul D, Lee J, Bae M, et al (2009) Comparison of growth factor and cytokine expression in patients with degenerated disc disease and herniated nucleus pulposus. Clin Biochem 42: 1504-1511.

48. Cuellar J, Golish S, Reuter M, Cuellar V, Angst M, et al. (2010) Cytokine evaluation in individuals with low back pain using discographic lavage. Spine $J$ 10: $212-218$

49. Kraychete D, Sakata R, Issy A, Bacellar O, Santos-Jesus R, et al. (2010) Serum cytokine levels in patients with chronic low back pain due to herniated disc: analytical cross-sectional study. Sao Paulo Med J 128: 259-262.

50. Doupis J, Lyons T, Wu S, Gnardellis C, Dinh T, et al. (2009) Microvascular 1 reactivity and inflammatory cytokines in painful and painless peripheral diabetic neuropathy. J Clin Endocrinol Metab 94: 2157-2163.
51. Purwata T (2011) High TNF-alpha plasma levels and macrophages iNOS and TNF-alpha expression as risk factors for painful diabetic neuropathy. J Pain Res 4: 169-175.

52. Alexander G, van Rijn M, van Hilten J, Perreault M, Schwartzman R (2005) Changes in cerebrospinal fluid levels of pro-inflammatory cytokines in CRPS. Pain 116: 213-219.

53. Uçeyler N, Eberle T, Rolke R, Birklein F, Sommer C (2007) Differential expression patterns of cytokines in complex regional pain syndrome. Pain 132 195-205.

54. Orozco L, Soler R, Morera C, Alberca M, Sánchez A, et al. (2011) Intervertebra Disc Repair by Autologous Mesenchymal Bone Marrow Cells: A Pilot Study. Transplantation Jul 25 [Epub ahead of print].

55. Yoshikawa T, Ueda Y, Miyazaki K, Koizumi M, Takakura Y (2010) Disc regeneration therapy using marrow mesenchymal cell transplantation: a report of two case studies. Spine 35: E475-480.

56. Alfaqeh H, Norhamdan M, Chua K, Chen H, Aminuddin B, et al. (2008) Cell based therapy for osteoarthritis in a sheep model: gross and histologica assessment. Med J Malaysia 63: 37-38.

57. Centeno C, Busse D, Kisiday J, Keohan C, Freeman M, et al. (2008) Regeneration of meniscus cartilage in a knee treated with percutaneously implanted autologous mesenchymal stem cells. Med Hypotheses 71: 900-908.

58. Centeno C, Schultz J, Cheever M, Robinson B, Freeman M, et al. (2010) Safety and complications reporting on the re-implantation of culture-expanded mesenchymal stem cells using autologous platelet lysate technique. Curr Stem Cell Res Ther 5: 81-93.

59. Guo W, Wang H, Zou S, Gu M, Watanabe M, et al. (2011) Bone marrow stroma cells produce long-term pain relief in rat models of persistent pain. Stem Cells. 2011; 29[8]:1294-303.

60. Shibata T, Naruse K, Kamiya H, Kozakae M, Kondo M, et al. (2008) Transplantation of bone marrow-derived mesenchymal stem cells improves diabetic polyneuropathy in rats. Diabetes 57: 3099-3107.

61. Waterman R, Tomchuck S, Henkle S, Betancourt A [2010] A new mesenchyma stem cell [MSC] paradigm: polarization into a pro-inflammatory MSC1 or an Immunosuppressive MSC2 phenotype. PLoS One 5: e10088.

62. Waterman R, Betancourt A (2011) The use of anti-inflammatory mesenchyma stem cells [MSC2] in a painful diabetic peripheral neuropathy mouse model Unpublished findings.

63. 2006 Voices of Chronic Pain Survey. 